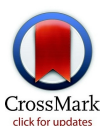

clickfor updates

\title{
Clinical, geographical, and temporal risk factors associated with presentation and outcome of vivax malaria imported into the United Kingdom over 27 years: observational study
}

\author{
Claire Broderick, ${ }^{1}$ Behzad Nadjm, ${ }^{2}$ Valerie Smith, ${ }^{1}$ Marie Blaze, ${ }^{1}$ Anna Checkley, ${ }^{2}$ Peter L Chiodini, \\ Christopher J M Whitty ${ }^{1}$
}

${ }^{1}$ Public Health England Malaria Reference Laboratory, London School of Hygiene \& Tropical Medicine, London WC1E 7HT, UK

${ }^{2}$ Hospital for Tropical Diseases, London, UK

Correspondence to:

C) M Whitty

christopher.whitty@lshtm.ac.uk Additional material is published online only. To view please visit the journal online (http:// dx.doi.org/10.1136/BMJ.h517) Cite this as: $B M J$ 2015;350:h1703 10.1136/bmi.h1703

Accepted: 3 March 2015

\section{ABSTRACT}

\section{OBJECTIVE}

To examine temporal and geographical trends, risk factors, and seasonality of imported vivax malaria in the United Kingdom to inform clinical advice and policy.

DESIGN

Observational study.

\section{SETTING}

National surveillance data from the UK Public Health England Malaria Reference Laboratory, data from the International Passenger Survey, and international climactic data.

\section{PARTICIPANTS}

All confirmed and notified cases of malaria in the UK ( $n=50187$ ) from 1987 to 2013 , focusing on 12769 cases of vivax malaria.

\section{MAIN OUTCOME MEASURES}

Mortality, sociodemographic details (age, UK region, country of birth and residence, and purpose of travel), destination, and latency (time between arrival in the UK and onset of symptoms).

RESULTS

Of the malaria cases notified, $25.4 \%(n=12769)$ were due to Plasmodium vivax, of which $78.6 \%$ were imported from India and Pakistan. Most affected patients (53.5\%) had travelled to visit friends and relatives, and $11.1 \%$ occurred in tourists. Imported $P$ vivax is concentrated in areas with large communities of south Asian heritage. Overall mortality was 7/12725
(0.05\%), but with no deaths in 9927 patients aged under 50 years. Restricting the analysis to those aged more than 50 years, mortality was $7 / 2798(0.25 \%)$, increasing to $4 / 526$ (0.76\%) (adjusted odds ratio 32.0, $95 \%$ confidence interval 7.1 to $144.0, \mathrm{P}<0.001$ ) in those aged 70 years or older. Annual notifications decreased sharply over the period, while traveller numbers between the UK and South Asia increased. The risk of acquiring $P$ vivax from South Asia was year round but was twice as high from June to September (40 per 100000 trips) compared with the rest of the year. There was strong seasonality in the latency from arrival in the UK to presentation, significantly longer in those arriving in the UK from South Asia from October to March (median 143 days) versus those arriving from April to September (37 days, $\mathrm{P}<0.001$ ).

\section{CONCLUSIONS}

Travellers visiting friends and family in India and Pakistan are most at risk of acquiring $P$ vivax, and older patients (especially those $>70$ years) are most at risk of dying; these groups should be targeted for advice before travelling. The risk of acquiring vivax malaria is year round but higher during summer monsoons, masked by latency. The latency of time to clinical presentation of imported vivax malaria in the UK is highly seasonal; seasonal latency has implications for pretravel advice but also for the control of malaria in India and Pakistan. A reduced incidence of vivax malaria in travellers may mean further areas of South Asia can be considered not to need malaria chemoprophylaxis.

\section{Introduction}

Plasmodium vivax is the most widely distributed of the species of parasite responsible for malaria, with up to 2.5 billion people at risk of vivax malaria worldwide, and an estimated 80 million to 300 million new cases each year. ${ }^{12}$ It is the commonest form of malaria outside Africa, and travellers to Asia, the Pacific countries and islands, Latin America, and parts of Africa are all potentially at risk. Vivax malaria has traditionally been described as "benign," but recent evidence indicates its potential to cause severe disease and death. ${ }^{123456}$ This has important implications for travellers to these regions, including those at minimal risk of falciparum malaria.

$P$ vivax historically accounts for about one quarter of the roughly 1500 cases of malaria notified in the United Kingdom each year. ${ }^{7}$ Understanding the epidemiology of imported vivax malaria, including risk factors for contracting the infection and severe disease, is therefore 
necessary to inform doctors providing advice and prophylaxis to potential travellers, and those seeing patients who have returned from Asia and Latin America. Despite this, few large studies have been done of imported vivax in non-endemic countries, with most data on malaria in travellers concentrating on falciparum malaria. Additionally, it is possible to answer questions about latency, seasonality, and relapse of vivax in imported cases in non-endemic countries because, unlike endemic countries, reinfection is not a possibility.

Unlike malaria caused by $P$ falciparum, vivax malaria can remain dormant in humans for months or years before causing one or more relapses of clinical malaria. This latency results from hypnozoite forms of the parasite, which develop and persist in the liver before later reactivating and causing blood stage infections, called relapses. ${ }^{8}$ Without treatment of these hypnozoites, reactivation may lead to recurrent clinical infections in the host. Latency and relapse may be influenced by external factors, including those related to geography and the seasons, ${ }^{910111213}$ but there are few studies large enough to investigate this latency, and it is difficult to explore in endemic areas owing to reinfection. Returning travellers thus provide an ideal opportunity for studying latency.

We examined all malaria cases notified in the UK over 27 years (1987 to 2013 inclusive), focusing on P vivax. We also analysed data on international passenger numbers to and from the UK and international climactic data. We aimed to identify important trends and at risk groups, to assist doctors in the UK and other non-endemic countries advising travellers on malaria prevention, to assist those assessing unwell returned travellers, and to inform guidance on chemoprophylaxis. We also assessed the latency of imported vivax cases and investigated potential seasonal effects, important for wider efforts at vivax control in Asia.

\section{Methods}

The Public Health England Malaria Reference Laboratory maintains the national surveillance database of reported cases of malaria in the UK. The laboratory identifies such cases from statutory notification through local authorities, laboratories sending blood films and blood samples for diagnostic verification, and clinicians sending standardised malaria reports. Parasitological confirmation through blood films, polymerase chain reaction, or tissue histology is required for inclusion on the database and in this study. Most films and polymerase chain reactions are validated at the national Malaria Reference Laboratory.

On notification of cases, clinicians are asked to complete a data collection form covering demographic and clinical data of the patient, including details of travel and illness. Capture-recapture analysis has estimated that about $56 \%$ of malaria cases in the UK are captured by this system, ${ }^{14}$ which is high by international standards. We included all reported cases of malaria in the UK from 1 January 1987 to 31 December 2013. The same team using virtually identical methods has collected these data over this period. Demographic factors including age, period of travel, reason for travel, geographical destination, time of arrival in the UK and diagnosis, and UK region are routinely prospectively collected. We entered data into dBase, which were validated, cleaned, and analysed using Stata 12 (StataCorp).

We calculated simple proportions, $\chi^{2}$ tests for significance of proportions, and odds ratios, and used logistic regression to calculate odds ratios adjusted for prespecified confounding factors (month and year of diagnosis, UK region of treatment, and country of travel). The Wilcoxon rank sum test was used for groups with skewed continuous data (mainly age).

To inform analysis of clinical and demographic data by providing a denominator, we obtained data on annual passenger numbers travelling to and from the UK from the International Passenger Survey, Office for National Statistics, a continuous questionnaire based survey of international passengers conducted at all major ports and routes into the UK. The survey uses a sample size of approximately 250000 passengers each year to provide estimates for UK travel and tourism. Fuller details of the methods are described elsewhere. ${ }^{15}$ Detailed data by country, including quarterly passenger numbers to and from the UK and purpose of travel, were available for 1993 to 2013. To inform data on seasonality of presentation, we obtained data on seasonal rainfall patterns in India and Pakistan from the Climactic Research Unit, University of East Anglia. Records of El Niño southern oscillation activity came from the US National Oceanic and Atmospheric Administration and from Liverpool University (personal communication, A Morse 2014).

\section{Results}

Between 1987 and 2013, 50187 cases of malaria were notified to the UK Malaria Reference Laboratory. Of these, 12769 (25.4\%) were related to $P$ vivax. For comparison, $65.5 \%$ of cases $(\mathrm{n}=32877)$ were due to $P$ falciparum, $6.0 \%$ to $P$ ovale $(\mathrm{n}=3010)$, and $1.6 \%$ to $P$ malariae $(n=797)$. In this study we grouped these three species together as "non-vivax malaria." The remaining 734 cases consisted of mixed infections ( $\mathrm{n}=570)$, not specified ( $\mathrm{n}=163)$, and $P$ knowlesi $(\mathrm{n}=1)$, and we excluded these from the subsequent analysis. Data completeness was good for central variables (outcome 99\%, age 99\%, country of travel $88 \%$, sex 94\%) and reasonable for most supplementary variables (country of birth $58 \%$, chemoprophylaxis 60\%).

The median age of patients with vivax malaria was 29 years (interquartile range 21-47 years), similar to patients with non-vivax malaria (32, 23-44 years), and $63 \%$ of patients with vivax and non-vivax malaria were male. Where data were recorded ( $n=7265)$, just $23 \%$ of patients with vivax malaria reported using antimalarial chemoprophylaxis. Most cases of vivax (4973/9302, $53.5 \%$ ) occurred in people generally of heritage from malaria endemic countries who had visited friends and relatives in countries with malaria. Tourism (11.4\%) and business travel (5.1\%) accounted for fewer cases (table 1). Most patients with vivax malaria (5507/7756, 71\%) were 


\begin{tabular}{lll}
\hline Table $\mathbf{1 |}$ Malaria notifications in the United Kingdom by purpose of travel, 1987-2013 \\
\cline { 2 - 3 } Po (\%) of cases & \\
\cline { 2 - 3 } Vurpose of travel & $4973(53.46)$ & $12319(49.63)$ \\
\hline New entrant resident to UK & $1212(13.03)$ & $1850(7.45)$ \\
\hline Foreign visitor ill in UK & $1047(11.26)$ & $2951(11.89)$ \\
\hline Holiday & $1036(11.14)$ & $3472(13.99)$ \\
\hline Business & $476(5.12)$ & $2133(8.59)$ \\
\hline UK citizen living abroad & $193(2.07)$ & $975(3.93)$ \\
\hline Other & $365(3.92)$ & $1122(4.52)$ \\
\hline Total No & 9302 & 24822
\end{tabular}

born outside the UK, and of the non-UK born patients with vivax malaria, most were born in South Asia (39.0\% (3000/7756) in India and 21.5\% (1669/7756) in Pakistan). In contrast, most of the non-UK born patients with falciparum malaria were born in West Africa.

Seven deaths were due to vivax malaria, giving an overall mortality of $0.05 \%$, with no deaths in the 9927 patients aged less than 50 years. By comparison, 215 deaths occurred in the non-vivax group, all from falciparum malaria, with an overall mortality of $0.58 \%$. The median age of those who died from vivax malaria was 72 years (interquartile range 52-75 years), significantly older than those who survived (30, 21-47 years, $\mathrm{P}=0.0002)$. Restricting the analysis to those aged more than 50 years, mortality was $7 / 2798(0.25 \%)$ and in those aged 70 years or older was $4 / 526(0.76 \%)$ compared with $0 \%$ in those aged less than 50 years. Patients aged 70 years and older were significantly more likely to die than those aged less than 70 years (odds ratio 31.0), and this difference remained when adjusted for the potential confounding factors of month and year of diagnosis, UK region of treatment, and country of travel (adjusted odds ratio $32.0,95 \%$ confidence interval 7.1 to $144.0, \mathrm{P}<0.001)$. Mortality was not affected significantly by country of travel, month and year of diagnosis, or UK region.

Over $80 \%$ of patients with vivax malaria had travelled to the South Asian subcontinent (table 2). The top

\begin{tabular}{|c|c|c|}
\hline \multirow[b]{2}{*}{ World region } & \multicolumn{2}{|l|}{ No (\%) of cases } \\
\hline & Vivax malaria & Non-vivax malaria \\
\hline South Asia* & $9148(81.1)$ & $629(2.0)$ \\
\hline South East Asia and Far East & $482(4.3)$ & $150(0.47)$ \\
\hline East Africa & $397(3.5)$ & $4453(14.0)$ \\
\hline Latin America & $347(3.1)$ & $48(0.15)$ \\
\hline New Guinea & $244(2.2)$ & $50(0.16)$ \\
\hline West Africa & $189(1.7)$ & $21511(67.2)$ \\
\hline Horn of Africa & $185(1.6)$ & $290(1.0)$ \\
\hline Africa unspecified & $113(1.0)$ & $1394(4.4)$ \\
\hline Southern Africa & $110(1.0)$ & $2181(6.8)$ \\
\hline Middle East & $36(0.3)$ & $12(0.04)$ \\
\hline Central Africa & $26(0.2)$ & $1229(3.8)$ \\
\hline North Africa & $4(0.04)$ & $1(0)$ \\
\hline Yemen & $5(0.04)$ & $47(0.1)$ \\
\hline Caribbean & $0(0)$ & $6(0.02)$ \\
\hline Blood transfusion & $0(0)$ & $1(0)$ \\
\hline Total No & 11286 & 32002 \\
\hline
\end{tabular}

five countries travelled to were India (48.3\%), Pakistan (30.3\%), New Guinea (2.2\%), Kenya (1.6\%), and Indonesia $(1.4 \%)(n=11286)$. This is in contrast with cases of non-vivax malaria in the UK where almost all of the patients were from Africa, particularly Nigeria and Ghana. For malaria cases imported from India, the Malaria Reference Laboratory recorded the region travelled to from 2006 onwards. Where multiple destinations within India were reported, we recorded the region as "India multiple." The highest numbers of vivax and non-vivax notifications were associated with travel to Maharashtra state, which includes Mumbai, but there were also significant numbers of patients with vivax malaria acquired in Gujarat, Goa, and the Punjab (table 3).

Given the distribution of ethnic groups in the UK, we analysed malaria notifications by UK region. ${ }^{16}$ London accounted for 4118 (32.3\%) of vivax cases, 3001 (23.5\%) were notified from the north west and 9.5\% from Yorkshire and the Humber. In contrast, just $7 \%$ of patients with non-vivax malaria came from the north west and Yorkshire and the Humber combined and 61\% from London. $P$ vivax was the most common malaria species to be notified from the north west $(65 \%)$ and from Yorkshire and Humber (55\%), but in London it accounted for just $15.5 \%$ of all malaria notifications, with P falciparum the predominant species (table 4).

The annual number of vivax cases decreased strongly from 1997 to 2003 before stabilising, at a time when notified cases of falciparum malaria were increasing. ${ }^{7}$ In particular there was a substantial reduction in vivax cases imported from India and Pakistan over this period, despite a steady increase in passenger numbers, including the high risk visiting friends and relatives group, travelling between the UK and India and Pakistan at this time (fig 1). For those travelling to India and Pakistan, the risk of acquiring vivax malaria reduced over this period, with an average of 77 cases per 100000 trips in the period 1993 to 1997 , compared with 12 cases per 100000 trips in the period 2009 to 2013 (fig 2). Figure 1 shows the years with increased El Niño southern oscillation activity.

Table 3 | Source of imported malaria in United Kingdom 2006-13, by Indian region

\begin{tabular}{lll} 
& \multicolumn{2}{l}{ No (\%) of cases } \\
\cline { 2 - 3 } Indian region & Vivax malaria & Non-vivax malaria \\
\hline Maharashtra (with Mumbai) & $103(30)$ & $13(28)$ \\
\hline Gujarat & $77(22)$ & $8(17)$ \\
\hline Goa & $51(15)$ & $11(23)$ \\
\hline Punjab & $40(12)$ & $0(0)$ \\
\hline West Bengal (with Kolkata) & $12(3)$ & $2(4)$ \\
\hline India multiple* & $12(3)$ & $4(9)$ \\
\hline Andhra Pradesh (with & $10(3)$ & $1(2)$ \\
Hyderabad) & & \\
\hline Delhi & $9(3)$ & $2(4)$ \\
\hline Tamil Nadu (with Chennai) & $9(3)$ & $1(2)$ \\
\hline Uttar Pradesh & $4(1)$ & $0(0)$ \\
\hline Other & $10(3)$ & $5(11)$ \\
\hline Not specified & $8(2)$ & $0(0)$ \\
\hline Total & 345 & 47 \\
\hline
\end{tabular}

*Travelled to multiple regions within India. 


\begin{tabular}{|c|c|c|c|c|c|}
\hline \multirow[b]{2}{*}{ UK region* } & \multirow[b]{2}{*}{$\begin{array}{l}\text { Regional } \\
\text { population } \\
\text { (2012) }\end{array}$} & \multicolumn{2}{|c|}{ Vivax malaria } & \multicolumn{2}{|c|}{ Non-vivax malaria } \\
\hline & & No (\%) & $\begin{array}{l}\text { Cases per } 100000 \\
\text { population } \\
(1987-2013)\end{array}$ & No (\%) & $\begin{array}{l}\text { Cases per } 100000 \\
\text { population } \\
(1987-2013)\end{array}$ \\
\hline London & 8308400 & $4118(32.3)$ & 49.6 & $22598(61)$ & 272.0 \\
\hline North west & 7084300 & $3001(23.5)$ & 42.4 & $1609(4.3)$ & 22.7 \\
\hline Yorkshire and the Humber & 5316700 & $1210(9.5)$ & 22.8 & $983(2.7)$ & 18.5 \\
\hline South east & 8724700 & $1495(11.7)$ & 17.1 & $4801(13)$ & 55.0 \\
\hline East & 5907300 & $944(7.4)$ & 16.0 & $2688(7.3)$ & 45.5 \\
\hline East Midlands & 4567700 & $516(4)$ & 11.3 & $661(1.8)$ & 14.5 \\
\hline Scotland & 5313600 & $432(3.4)$ & 8.1 & $844(2.3)$ & 15.9 \\
\hline South west & 5339600 & $374(2.9)$ & 7.0 & $1424(3.8)$ & 26.7 \\
\hline West Midlands & 5642600 & $336(2.6)$ & 6.0 & $396(1.1)$ & 7.0 \\
\hline Wales & 3074100 & $155(1.2)$ & 5.0 & $432(1.2)$ & 14.1 \\
\hline North east & 2602300 & $114(0.9)$ & 4.4 & $389(1)$ & 14.9 \\
\hline Northern Ireland & 1823600 & $43(0.3)$ & 2.4 & $113(0.3)$ & 6.2 \\
\hline Channel Islands & - & $14(0.1)$ & - & $42(0.1)$ & - \\
\hline Other or not specified & - & $17(0.2)$ & - & $76(0.1)$ & - \\
\hline Total & - & 12769 & - & 37056 & - \\
\hline
\end{tabular}

*Office for National Statistics. Region and country profiles: population and migration, 19 December 2013.

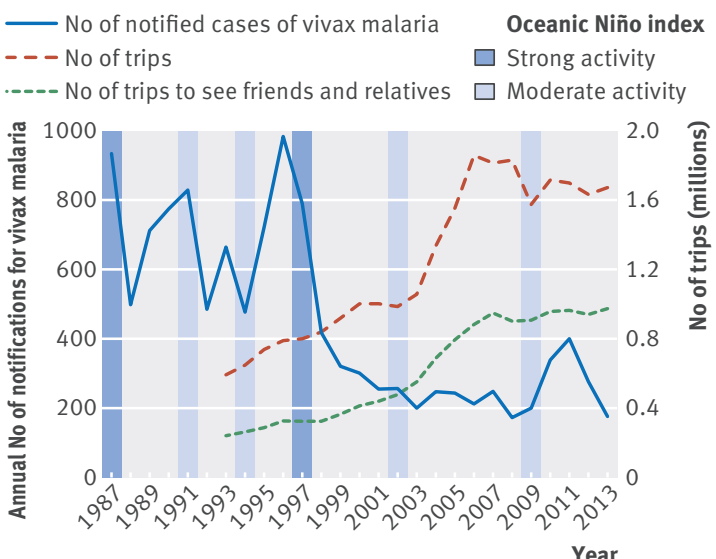

Fig 1 | All reported cases of Plasmodium vivax malaria in the United Kingdom, 1987-2013, and passenger numbers to India and Pakistan

\section{Latency}

The majority of cases of vivax malaria (8923/12157, $73.4 \%$ ) were diagnosed in the summer months of April to September, and just $26.6 \%$ were diagnosed from October to March (fig 3). This does not reflect seasonal changes

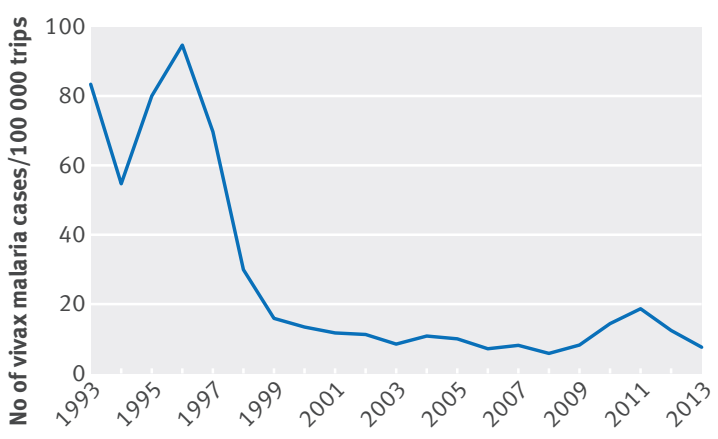

Year

Fig 2 | Annual cases of Plasmodium vivax imported from India and Pakistan per 100000 trips, 1993-2013

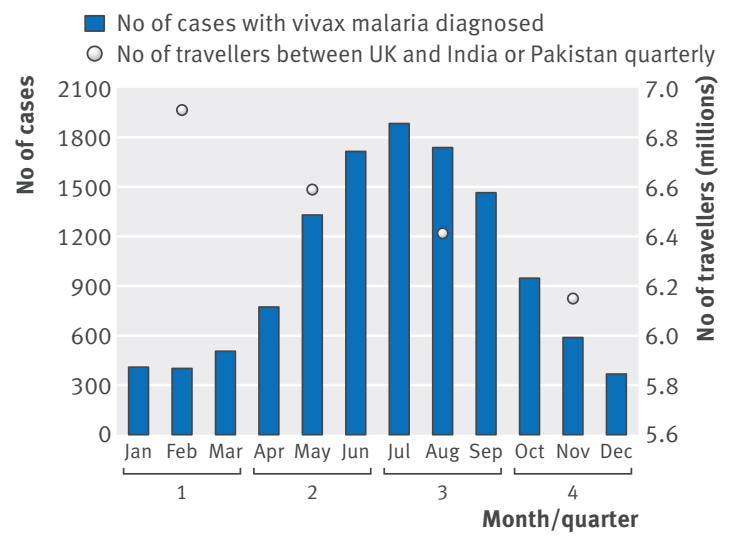

Fig 3 | Total number of cases with vivax malaria diagnosed per month in the United Kingdom, 1987-2013 and quarterly passenger numbers between the UK and India and Pakistan, 1993-2013

in passenger numbers, as the peak in travellers between the UK and India and Pakistan is in the first quarter of the year (fig 3). Based on month of arrival in the UK after which infection is essentially impossible, although the peak of cases is in the monsoon period, the risk of acquiring vivax malaria from India and Pakistan was much more evenly distributed year round; although still twice as high for those returning in the third quarter of the year (July to September, 40 cases per 100000 trips) compared with the rest of the year (table 5).

Specifically, latency was calculated as the number of days between the date of arrival in the UK and the date of onset of symptoms. The median latency was 68 days (interquartile range 9-212 days). This latency varied substantially according to the time of year the traveller arrived in the UK: it was significantly longer for those arriving in winter (October to March, 120 days) compared with those arriving in summer (April to September, 41 days, $\mathrm{n}=6777, \mathrm{P}<0.001$ ) (fig 4 ), meaning vivax malaria was acquired by infection all year through, but largely presented in the summer months. This seasonal 


\begin{tabular}{|c|c|c|c|}
\hline Quarter & $\begin{array}{l}\text { Total No of cases notified } \\
\text { per quarter, imported from } \\
\text { India and Pakistan }\end{array}$ & $\begin{array}{l}\text { Total No of trips } \\
\text { between UK and India/ } \\
\text { Pakistan per quarter }\end{array}$ & $\begin{array}{l}\text { Risk of acquiring } \\
P \text { vivax per } 100000 \\
\text { trips to India/Pakistan }\end{array}$ \\
\hline Jan-Mar & 960 & 6908593 & 13.9 \\
\hline Apr-Jun & 1250 & 6585788 & 19.0 \\
\hline Jul-Sep & 2564 & 6411098 & 40.0 \\
\hline Oct-Dec & 1139 & 6144258 & 18.5 \\
\hline
\end{tabular}

difference in latency was apparent for cases imported from India and Pakistan (median 37 days April to September versus 143 days October to March, $\mathrm{P}<0.001$ ) (fig 5), where the period of shortest latency coincided with the period of peak rainfall in India and Pakistan (fig 6). We found no significant seasonal differences in latency for the highly heterogeneous cases imported from the widely geographically scattered countries other than India and Pakistan (where monsoons are therefore not clustered in time) with latency 51 days April to September versus 66 days October to March ( $\mathrm{P}=0.54$ ) (fig 5).

\section{Discussion}

Plasmodium vivax accounts for one quarter of malaria notifications in the United Kingdom but is the cause of most cases of imported malaria in parts of the UK outside London, especially the north west. Most UK cases occur in travellers to India and Pakistan, particularly those visiting friends and relatives. Although the overall mortality rate is low, older patients are at a substan-

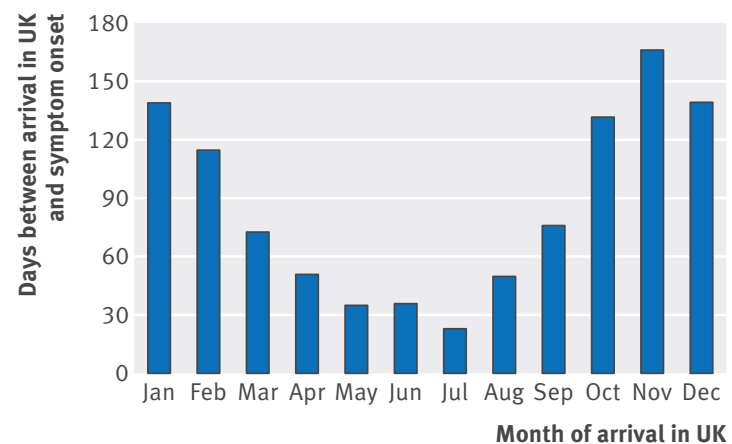

Fig 4 | Latency between arrival in United Kingdom and onset of symptoms, by month of arrival in UK, 1987-2013

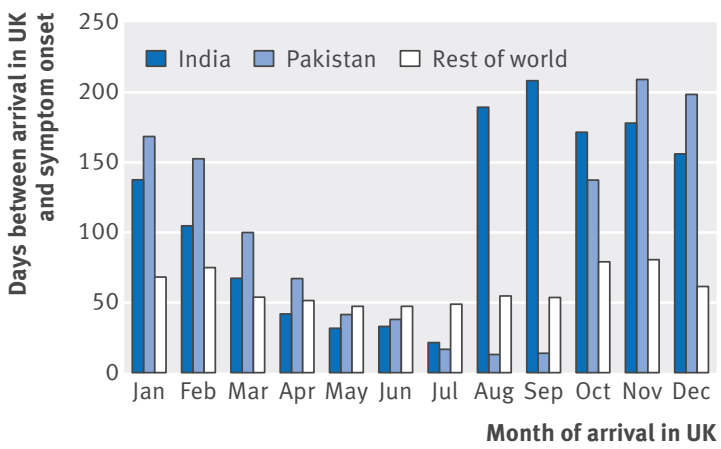

Fig 5 Latency between arrival in United Kingdom and onset of symptoms, by month of arrival in UK, for India, Pakistan, and rest of world, 1987-2013

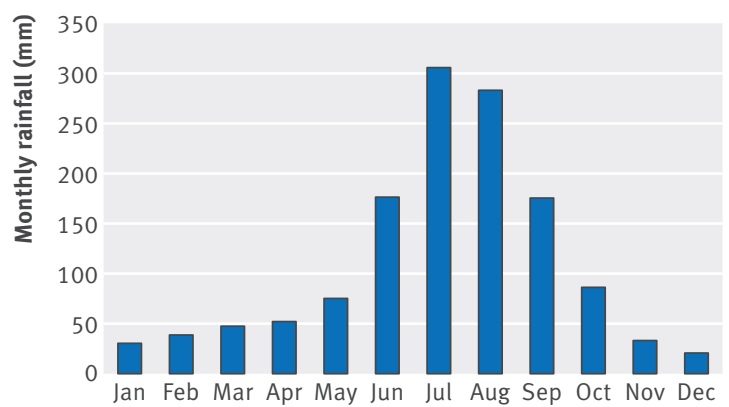

Month

Fig 6 | Average monthly rainfall in India and Pakistan, 1990-2009. Adapted using open database data from the Climactic Research Unit, University of East Anglia

tially increased risk of dying; in the UK elderly patients are more likely to die of vivax malaria than the average traveller patient is of falciparum malaria, and all deaths are in those aged more than 50 years.

The risk of acquiring vivax malaria in India and Pakistan is year round, although higher during the summer months, but latency between arrival in the UK and the onset of symptoms is highly seasonal. Consequently, vivax malaria tends to present in the summer months, regardless of the time of year that the infection is acquired. Doctors should remember to take a full travel history, and patients travelling to India and Pakistan should be warned to mention travel even if presenting unwell months later. Annual notifications declined strongly to a low steady state over the study period, despite increasing passenger numbers to India and Pakistan, suggesting the risk to travellers of acquiring vivax has reduced. Advice on malaria chemoprophylaxis has recently changed in the UK to reflect this reduced risk of vivax malaria. ${ }^{17}$ Further change with fewer destinations requiring prophylaxis should be considered, but elderly patients in particular should be viewed as vulnerable. The clear seasonal latency has implications for malaria control in India and Pakistan and possibly beyond. Specifically, control measures targeted at reducing transmission at the peak of clinical cases of vivax malaria during the monsoon will have a smaller effect on incidence than would be anticipated. This is because new infections are much more widely distributed over the year than the peak of clinical cases would imply, as latency of relapse results in clustering of cases.

\section{At risk groups}

People of south Asian heritage from vivax endemic countries who are travelling to visit friends and relatives in countries with malaria are at the greatest risk for acquiring vivax malaria. The "visiting friends and relatives" group is known to be high risk for people of African heritage acquiring falciparum malaria while abroad compared with tourists, ${ }^{7} 1819$ and it is likely that similar factors lie behind this trend for vivax malaria. This group may spend longer periods in endemic areas and stay in areas (especially rural ones) with higher malaria transmission rates compared with tourists. ${ }^{18} 20$ 
This group is also less likely to seek health advice before travelling or to use chemoprophylaxis. ${ }^{21}{ }^{22}$ Self reported use of prophylaxis in patients with malaria was low. Most patients with vivax malaria probably do not represent failure of prophylaxis, especially as none of the chemoprophylactic agents currently advised for UK travellers kill hypnozoites, so their action is limited to prevention of a primary infection. Improving uptake of chemoprophylaxis where relevant and use of bite prevention strategies among those visiting friends and relatives is an ongoing public health challenge.

Older patients had a significantly greater risk of dying from vivax malaria than younger patients. This adds to previous studies that have shown old age to be an independent risk factor for death from imported falciparum malaria and means that vivax malaria should not be considered a benign disease in older age groups. ${ }^{232425}$ The mechanism is unclear; increasing numbers of comorbidities and possibly higher parasitaemias $^{26}$ are thought to contribute, but there is ample evidence that elderly patients are more at risk of many infections, and vivax malaria is no exception. Therefore it is important that older travellers to vivax malaria endemic regions, particularly those visiting family or friends, are encouraged to attend for pretravel counselling, offered chemoprophylaxis, and warned to present early with fevers in the year after return. It is especially important for this age group to be aware that chemoprophylaxis can prevent initial attacks of vivax malaria but not relapses.

\section{Ethnicity and geographical clustering in the UK}

The UK's demography and its longstanding ties with South Asia are the likely cause for the higher rates of vivax malaria in the UK compared with some other European countries. ${ }^{27}$ We anticipate that other countries, such as Canada, with large South Asian diaspora would also have higher rates of vivax malaria. The differing geographical distributions of $P$ vivax and nonvivax malaria notifications in the UK reflect regional differences in migration and ethnicity. Cases of falciparum malaria cluster in London where there are large numbers of West African communities who are at risk when they travel to visit relatives and friends. Few large West African communities occur beyond the south east, resulting in fewer cases of falciparum malaria outside this region. In contrast, cases of vivax malaria are spread between London and the south east as well as the north west, Yorkshire and the Humber, and the Midlands. This reflects the distribution of South Asian communities, who are at risk of vivax malaria when they travel to visit family and friends in India and Pakistan (see supplementary figures). ${ }^{28}$ Doctors working in South Asian communities are likely to encounter large numbers of patients at risk of vivax malaria who may not present for pretravel advice, so all opportunities should be taken to target this group during routine care.

\section{Latency and seasonality}

The variable latency exhibited by $P$ vivax means that travellers may develop clinical malaria many months or even years after returning from an endemic region. In this study, the median latency between arriving in the UK and developing symptoms was 68 days. Long latency presents a challenge to general practitioners and hospital doctors when they are assessing patients, as travel taking place long ago may be overlooked or not mentioned by patients, making diagnosis difficult.

The peak of vivax malaria presenting in the UK corresponds to the monsoons in India and Pakistan irrespective of time travelled. This is likely to reflect both increased numbers of patients acquiring vivax malaria during the rains (higher incidence) and presenting with primary infections, but a major component is from relapses by hypnozoites in patients who travelled outside this period (seasonal latency). Detecting latency is not easy in endemic countries because reinfection and relapse are not easily differentiated. As this study was in a non-endemic country, there was no realistic possibility of reinfection, which makes the investigation of latency much easier. ${ }^{29}$ The data shown in figures 3 and 4 therefore provide evidence of the seasonality of the latency of vivax malaria from India and Pakistan. These findings are supported by earlier smaller studies showing that vivax malaria tends to present in the summer months in the UK, regardless of when the disease was acquired. ${ }^{13} 303132$ It has been proposed that this seasonality is due to the effects of warmer weather in the British summer on the parasite's behaviour. However, if local weather was responsible for precipitating relapse, all cases of vivax malaria would be expected to demonstrate this phenomenon, regardless of the country of origin; we found no significant seasonal difference in latency for vivax malaria imported from the rest of the world.

It seems more likely that vivax malaria from India and Pakistan is adapted to relapse during the monsoon season when the prevalence of mosquitoes is at its peak and the chances of infection are therefore highest. This adaptation persists when the parasite is imported to non-endemic countries such as the UK. The UK does not have sufficient numbers of patients with vivax malaria imported from individual countries outside South Asia for reliable seasonal analysis, even when data are pooled over many years. There are well known differences between strains in the length of time hypnozoites remain dormant, 33 and it would be a useful area to explore further (for example, malaria from Latin America imported into the United States) as there is evidence of geographical variation. ${ }^{35}$ The stimuli that lead to activation of hypnozoites at specific time points are not known. ${ }^{36} 3738$

This latency has important implications for malaria control as it shows that apparent peaks in parasitaemia during the monsoon season will hide year round transmission. Several strategies have been proposed and implemented that target only the seasonal peak for malaria. This makes sense for falciparum malaria (which does not have hypnozoites). ${ }^{39}$ These latency data suggest, however, that for vivax malaria a much higher proportion of transmission occurs outside 
monsoon periods than absolute numbers of clinical cases would predict.

Trends over time and advice on chemoprophylaxis The substantial reduction in annual notifications of vivax malaria in the UK over the study period, particularly from India and Pakistan, occurred despite increasing numbers of international passengers to the region over the same period. The decrease in the number of vivax cases per 100000 trips to India and Pakistan over the period implies that the risk of acquiring vivax malaria while travelling to these countries has considerably reduced. From 2000 to 2012, the reported annual incidence of vivax malaria within India halved, ${ }^{40}$ and it is likely this has contributed to the decrease in the number of cases of vivax malaria among travellers. Other factors, such as increasing travel to urban rather than rural areas and changing rates of taken (as opposed to advised) prophylaxis may have also contributed. It is important for prescribers to be aware that in South Asia short epidemics of malaria can still occur. In Pakistan the annual incidence of $P$ vivax, which was stable, has more than doubled since 2008,40 and some European countries have reported increasing numbers of cases of vivax malaria imported from Pakistan in recent years, 4142 but not the UK. Recently the UK Advisory Committee on Malaria Prevention reduced the number of areas of Asia, and specifically India, where malaria chemoprophylaxis is recommended. In India, chemoprophylaxis is now recommended only for travel to Assam, Orissa, and specific districts in Andhra Pradesh and Madhya Pradesh. ${ }^{17}$ These data show why this reduction is possible, and further reductions may be rational given the small but important risk of using chemoprophylactic drugs if imported cases decrease further. Chemoprophylaxis advice is about balancing risk; if the risk of malaria decreases but the risk of the drug stays static the relative benefits of chemoprophylaxis against vivax malaria in South Asia decrease. However, despite the decreasing incidence of imported vivax malaria, the residual risk of vivax malaria remains for travellers to large areas, especially of Asia and Latin America, making decisions about chemoprophylaxis for high risk groups such as elderly people more difficult.

\section{Limitations of this study}

This was a large scale study using standardised national data collected prospectively and identically by the same team over many years. It has unavoidable limitations, some of which are common to all surveillance data. The Malaria Reference Laboratory operates a passive case detection system, which relies on the clinician or laboratory reporting cases of malaria, so under-reporting is inevitable. While it is estimated that more than half of UK cases are captured by this surveillance system, ${ }^{14}$ which is high by international standards, the true burden of vivax malaria in the UK is likely to be underestimated.

Case detection rates may vary, as some units may disproportionately under-report cases and this may change over time. Data collection methods did not, however, vary over the period of the study, so this is fairly unlikely to affect trends reported here. Data completeness was good for central variables but less so for supplementary ones, which is a common problem when using routinely collected data. We did not have reliable data on the specifics of chemoprophylaxis use, so were unable to investigate robustly the relation between this and latency. ${ }^{43}$ Similarly, there were no reliable data on length of stay. Until recently, second and subsequent relapses were not recorded systematically on the database, so we were unable to determine confidently whether each case was a first or repeat presentation. While this meant we could not investigate recurrent relapses in this study, it will not have affected the trends described here.

Given the study's concentration on vivax malaria the number of deaths recorded over the study period was inevitably low except in elderly people, making detailed comparisons of mortality rates difficult. There are alternative sources to the international passenger survey, ${ }^{44}$ with different methods. Several sources can provide slightly different estimates for passenger numbers from the UK to South Asia but have similar trends, in the sense that none suggest a peak at the same time as vivax malaria peaks.

\section{Implications of findings}

In the UK, travellers visiting family and friends in India and Pakistan are most at risk of acquiring vivax malaria, and older patients, especially those aged more than 70 years are most at risk of dying, so these groups should be targeted for pretravel advice and, where relevant, prophylaxis. The incidence of malaria has decreased significantly in travellers to South Asia, and it is reasonable to limit the areas where chemoprophylaxis is recommended. Raw data on date of presentation are misleading; the risk of acquiring vivax malaria is year round, although higher in the summer months, so prophylaxis should be offered to these groups regardless of month of travel. Clinical presentation of imported vivax malaria in the UK is highly seasonal, with clear evidence of seasonality of latency. This latency has implications for malaria control: compared with falciparum malaria, seasonal strategies to control malaria based on peaks of clinical presentation may not be as appropriate for vivax malaria as the incidence by season might predict.

The Malaria Reference Laboratory is supported by Public Health England. We thank all patients, clinicians, and laboratories from across the United Kingdom who submit the information on malaria, and the technical staff of the Malaria Reference Laboratory and Colin Sutherland for helpful comments. PLC is supported by the National Institute for Health Research University College London Hospitals Biomedical Research Centre. We thank Jane Jones (Public Health England) for permission to use the map showing proportions of patients from central and West Africa and South Asia in each local authority area of England and Wales (see supplementary file on bmj. com). ${ }^{28}$

Contributors: $C B, B N$, and $C J M W$ devised the study. MB and VS collected the data. $C B, B N$, and $A C$ validated the data. $C B$ and $C J M W$ analysed the data. All authors wrote the paper. $C B$ is the guarantor. Funding: Public Health England (UK Health Protection Agency before 2013).

Competing interests: All authors have completed the ICMJE uniform disclosure form at www.icmje.org/coi disclosure.pdf and declare: no 
support from any organisation for the submitted work; no financial relationships with any organisations that might have an interest in the submitted work in the previous three years; no other relationships or activities that could appear to have influenced the submitted work.

Ethical approval: Not required for analysis of data routinely collected by Public Health England. In common with other notification data, specific consent was not obtained but the presented data are anonymised and risk of identification is low.

Data sharing: The anonymised dataset is available to academic researchers from Public Health England Malaria Reference Laboratory or the corresponding author (christopher.whitty@lshtm.ac.uk).

Transparency: The lead (CB) author affirms that the manuscript is an honest, accurate, and transparent account of the study being reported; that no important aspects of the study have been omitted; and that any discrepancies from the study as planned (and, if relevant, registered) have been explained.

1 Price RN, Tjitra E, Guerra CA, et al. Vivax malaria: neglected and not benign. Am J Trop Med Hyg 2007;77(6 Suppl):79-87.

2 Mueller I, Galinski MR, Baird JK, et al. Key gaps in the knowledge of Plasmodium vivax, a neglected human malaria parasite. Lancet Infect Dis 2009;9:555-66.

3 Baird JK. Neglect of Plasmodium vivax malaria. Trends Parasitol 2007:23:533-9.

4 Quispe AM, Pozo E, Guerrero E, et al. Plasmodium vivax hospitalizations in a monoendemic malaria region: severe vivax malaria? Am J Trop Med Hyg 2014;91:11-7.

5 Kochar DK, Saxena V, Singh N, et al. Plasmodium vivax malaria. Emerg Infect Dis 2005;11:132-4

6 Barcus MJ, Basri H, Picarima H, et al. Demographic risk factors for severe and fatal vivax and falciparum malaria among hospital admissions in northeastern Indonesian Papua. Am / Trop Med Hyg 2007;77:984-91

7 Smith AD, Bradley DJ, Smith V, et al. Imported malaria and high risk groups: observational study using UK surveillance data 1987-2006. BMJ 2008;337:a120

8 Krotoski W. A. Discovery of the hypnozoite and a new theory of malarial relapse. Trans R Soc Trop Med Hyg 1985;79:1-11.

9 Battle KE, Karhunen MS, Bhatt S, et al. Geographical variation in Plasmodium vivax relapse. Malar J 2014;13:144

10 Lover AA, Coker RJ. Quantifying effect of geographic location on epidemiology of Plasmodium vivax malaria. Emerg Infect Dis 2013;19:1058-65.

11 White NJ. Determinants of relapse periodicity in Plasmodium vivax malaria. Malar /2011:10:297.

12 Bottieau E, Clerinx J, Van Den Enden E, et al. Imported nonPlasmodium falciparum malaria: a five-year prospective study in a European referral center. Am J Trop Med Hyg 2006;75:133-8.

13 Willocks L, Jones M, Brettle R, et al. Changing patterns of malaria in south-east Scotland: implications for practitioner awareness and prophylactic advice. Postgrad Med J 1992;68:22-5.

14 Cathcart SJ, Lawrence J, Grant A, et al. Estimating unreported malaria cases in England: a capture-recapture study. Epidemiol Infect 2010;138:1052-8.

15 Office for National Statistics. 2014. www.ons.gov.uk/ons/ guide-method/method-quality/specific/travel-and-transportmethodology/international-passenger-survey/index.html.

16 Office for National Statistics. 2014. www.ons.gov.uk/ons/ guide-method/geography/beginner-s-guide/administrative/england/ government-office-regions/index.html.

17 Chiodini PL, Field V K, Whitty CJM, et al. Guidelines for malaria prevention in travellers from the United Kingdom 2014. Public Health England, 2014.

18 Schlagenhauf P, Steffen R, Loutan L. Migrants as a major risk group for imported malaria in European countries. J Travel Med 2003:10:106-7.

19 Angell SY, Cetron MS. Health disparities among travellers visiting friends and relatives abroad. Ann Intern Med 2005;142:67-72

20 Angell SY, Behrens RH. Risk assessment and disease prevention in travellers visiting friends and relatives. Infect Dis Clin North Am 2005; 19:49-65.

21 Scolari C, Tedoldi S, Casalini C, et al. Knowledge, attitudes, and practices on malaria preventive measures of migrants attending a public health clinic in northern Italy. J Travel Med 2002;9:160-2

22 Dos Santos CC, Anvar A, Keystone JS, et al. Survey of use of malaria prevention measures by Canadians visiting India. CMA 1999;160:195-200

23 Checkley AM, Smith A, Smith V et al. Risk factors for mortality from imported falciparum malaria in the United Kingdom over 20 years: an observational study. BMJ 2012;344:e2116

24 Greenberg AE, Lobel HO. Mortality from Plasmodium falciparum malaria in travelers from the United States, 1959 to 1987. Ann Intern Med 1990;113:326-7.

25 Muhlberger N, Jelinek T, Behrens RH, et al. Age as a risk factor for severe manifestations and fatal outcome of falciparum malaria in European patients: observations from TropNetEurop and SIMPID Surveillance Data. Clin Infect Dis 2003;36:990-5

26 Gjorup IE, Ronn A. Malaria in elderly non-immune travellers. / Travel Med 2002;9:91-3.

27 Mühlberger N, Jelinek T, Gascon J, et al. Epidemiology and clinical features of vivax malaria imported to Europe: sentinel surveillance data from TropNetEurop. Malar J 2004;3:5.

28 Health Protection Agency. Migrant Health. Infectious diseases in non-UK born populations in England, Wales and Northern Ireland. A baseline report-2006. November 2006.

29 Nolder D, Oguike MC, Maxwell-Scott H, et al. An observational study of malaria in British travellers: Plasmodium ovale wallikeri and Plasmodium ovale curtisi differ significantly in the duration of latency. BMJ Open 2013;3.pii:e002711.

30 Venkatesan P, Dedicoat M, Innes JA, et al. Seasonality of presentation of imported Plasmodium vivax malaria in Birmingham, UK. Trans $R$ Soc Trop Med Hyg 2003;97:550.

31 Warwick R, Swimmer GJ, Britt RP. Prolonged incubation period of imported P. vivax malaria in London. J $R$ Soc Med 1980;73:333-6.

32 Walker $E$. The seasonal pattern of Plasmodium vivax malaria in Glasgow. J Infect 1983;7:227-30.

33 Garnham PCC. Malaria parasites of man: life-cycles and morphology. In: Wernsdorfer WH, McGregor IA, eds. Malaria: principles and practice of malariology. Churchill Livingstone; 1988:69.

34 White NJ. Determinants of relapse periodicity in Plasmodium vivax malaria. Malar / 2011;10:297.

35 Battle KE, Karhunen MS, Bhatt S, et al. Geographical variation in Plasmodium vivax relapse. Malar J 2014;13:144

36 Shanks GD, White NJ. The activation of vivax malaria hypnozoites by infectious diseases. Lancet Infect Dis 2013;13:900-6.

37 Dembélé L, Franetich JF, Lorthiois A, et al. Persistence and activation of malaria hypnozoites in long-term primary hepatocyte cultures. Nat Med 2014;20:307-12.

38 Barnwell JW, Galinski MR. Malarial liver parasites awaken in culture. Nat Med 2014;20:237-9.

39 Cairns M, Roca-Feltrer A, Garske T, et al. Estimating the potential public health impact of seasonal malaria chemoprevention in African children. Nat Commun 2012:3:881.

40 World Health Organization. World malaria report: 2013. WHO, 2013.

41 Stark K, Schöneberg I. Increase in malaria cases imported from Pakistan to Germany in 2012. Euro Surveill 2012;17(47):pii=20320.

42 Odolini S, Gautret P, Kain KC, et al. Imported Plasmodium vivax Malaria ex Pakistan. J Travel Med 2014;21:314-7.

43 Schwartz E, Parise M, Kozarsky P, et al. Delayed onset of malariaimplications for chemoprophylaxis in travelers. N Engl J Med 2003;349:1510-6.

44 Government of India. Tourism statistics 2013 (New Delhi 2013) http:// tourism.gov.in/writereaddata/CMSPagePicture/file/marketresearch/ publications/IndiaTourismStatics2013_1.pdf.

Web appendix 1: Cases of vivax malaria per 1000000 population by UK region, 1987-2013

Web appendix 2: \% of population born in Central and West Africa and South Asia, living in each local authority area in England and Wales

(C) BMJ Publishing Group Ltd 2015 